\title{
Falls in the elderly: a reflective study
}

\begin{abstract}
This research aimed to reflect on falls in the elderly, comparing sociodemographic, clinical, health and functional variables among the elderly who had falls; checking the factors associated with falls in the elderly. A qualitative, descriptive study of the type of study of methodological reflection. It can be noticed that the highest proportion among the elderly who had fall was the female; with 80 years or more according to the studies analyzed; who had two or more morbidities and used five or more drugs. Falls were associated with females; aged 80 years or older and who had two or more morbidities. The study reinforces the need for investment in health promotion and morbidity prevention, considering that, among the predictors of falls, only the presence of comorbidities is amenable to intervention of the health professional. As well as growth for the health sciences.
\end{abstract}

Keywords: health of the elderly, evaluation studies as topic, nursing
Volume 3 Issue 5 - 2018

\author{
Maurício CS Cunha Lima, Maria do \\ Livramento Silva Bitencourt Edienne \\ Rosângela Sarmento Diniz, Cecília NGA \\ Valença \\ Master of Nursing, Lauro Wanderley University Hospital, Brazil
}

Correspondence: Maria do Livramento Silva Bitencourt, Master of Nursing, Lauro Wanderley University Hospital, Brazil, Email luiznascimento@outlook.com.br

Received:September 15, 2018 | Published: September 24, 2018

\section{Introduction}

Aging is a dynamic and progressive process in which there are morphological, functional and biochemical changes, reducing the capacity of homeostatic adaptation to situations of functional overload, progressively altering the organism and making it more susceptible to intrinsic and extrinsic aggressions. ${ }^{1}$

It represents the passage of time, not the pathology, being a natural and physiological process, in which the emotional, psychological and environmental experiences make it singular and individual. In this way, two people do not age identically. In recent decades, there has been a clear process of demographic aging. The United Nations (UN) considers the period from 1975 to 2025 the Age of Aging. ${ }^{2}$

In Brazil, the expectation of the Brazilian Institute of Geography and Statistics (IBGE) is that the population over 60 years of age is approximately $11 \%$ of the general population by the year 2020 . The aging index shows that for every 100 young individuals, there are 35.4 over 60 years. Life expectancy, which was around 33.7 years in $1950 / 55$, rose to 50.99 in 1990 , reached 66.25 in 1995 and is expected to reach 77.08 in $2020 / 2025$. $^{3}$

This process of demographic aging has repercussions and continues to affect the different spheres of society's social, economic, political and cultural structure, since the elderly, like the other age groups (children, youth and adults), have specific demands for obtaining adequate living conditions. Such demands have aroused great interest in the area of public health. ${ }^{4,5}$

One of the major concerns related to aging is that the increase in life expectancy is associated with a high rate of comorbidities. Postural instability and falls are part of the geriatric syndromes that encompass the most common health alterations in the elderly, constituting one of the main clinical and public health problems due to their high incidence, the consequent complications to health and the high care costs. ${ }^{6,7}$

Fall can be defined as "an unintended event that results in the individual's changing position to a lower level, relative to their initial position". Some authors refer to fall as a geriatric syndrome because it is considered a multifactorial and heterogeneous event. ${ }^{8}$
Approximately $30 \%$ of individuals over 65 years of age fall at least once a year, of which half are recurring. People of all ages are at risk of falling. However, for the elderly, they have a very relevant meaning, as they can lead to incapacity, injury and death. Its social cost is immense and becomes greater when the elderly have a decrease in autonomy and independence or need to be institutionalized. ${ }^{9}$

Falls usually have a multifactorial etiology and their causative factors are classified as: intrinsic, ie those resulting from physiological changes related to aging, diseases and effects caused by the use of drugs; and extrinsic factors that are factors that depend on social and environmental circumstances that create challenges for the elderly. These factors interact as determining and predisposing agents, both for accidental falls and for recurrent falls. ${ }^{10}$

This complexity of the etiology of falls, associated to the serious consequences of these, impose on health professionals the great challenge of identifying the possible risk factors and treating the etiological factors and comorbidities present. The importance of identifying these risk factors is reinforced by the greater success of interventions that are based on the early identification of the elderly with a greater chance of suffering falls and particularly those who, in addition to the risk of falls, are also at increased risk of suffering serious injuries of the same. ${ }^{11}$

Falls in the elderly are a frequent problem with important physical, psychological and social consequences. Among the main consequences of falls are the fractures, which seem to impute to the elderly greater vulnerability to new episodes, regardless of their frequency. Among other consequences of falls are head injuries, severe injuries, anxiety, depression and the so-called "fear of falling" (fear of subsequent falls), which can also affect elderly people who have never fallen. ${ }^{12}$

Thus, the purpose of this study of a reflexive, qualitative and methodological nature is to reflect, according to the information in the pertinent literature, about falls in the elderly. Justifying the need to expand and explore the proposed theme with the guiding question: Is the scientific academy currently reflecting on falling in the elderly? 


\section{Method}

This is a narrative, reflective, descriptive review of a qualitative approach. The study was conducted in September 2018, without temporal cut-off, using the EBSCO Database. The descriptors used were: Health of the Elderly. Evaluation Studies as Topic. Nursing. As inclusion criteria, original articles were used that included the theme about falls in the elderly. And as exclusion criteria: review studies, experience reports, reflection studies, theses and dissertations, manuals, case studies, updating and articles that were not available in full. ${ }^{13}$

The search allowed the location of 22 (twenty two) publications on the subject, where 10 (ten) original articles were included in the study, where all the articles chosen share the theme. The present study occurred in a descriptive reflective character, where the first step was to delimit the descriptors. ${ }^{13}$

The theoretical-methodological assumption of reflective study privileges the relationship between the subject and the contexto social, and presents a study perspective that articulates areas of knowledge and understands them as complementary and non-exclusive contributions to unveil a reality or phenomenon in its totality/complexity. ${ }^{13,14}$

Still, in the case of a theoretical-reflexive study, the elaboration of this article followed the assumptions of the a literature review, the process of which is a how to systematize information on issues in a robust body of knowledge, with the purpose of evaluating and summarizing the information found. The methodological approach included, first, the bibliographic survey, for medium of which an exploratory research was carried out and systematics of documents in electronic format present in the relevant literature bases in order to leverage the research. ${ }^{13,14}$

\section{Results and discussion}

In Brazil, the Ministry of Health defines one of the priorities is attention to the elderly. That decision was made in the review of the objectives and goals of the Pact for Life policy, taking into account the need to identify the elderly in situation of fragility or risk of embrittlement, develop actions for the promotion and prevention of improvement of quality of care to this population..$^{14,15}$

Population growth among the elderly is reality experienced in all the world, mainly developed and developing countries. The current scenario can be equivalence found in the number of publications selected for this study, since they were 8 international articles identified who emphasized the relevance of this topic. Such observation may be a reflection of the the scientific community to understand the aging process of the population and identify new health demands. ${ }^{16}$

This also corroborates the statement above is the question of the articles emphasizing the need for more research investments epidemiological and interventional aging, especially those aimed at to institutionalized elderly. It stands out importance of carrying out scientific studies with longitudinal cuts and compromised in monitor changes in the social profile and health of this population. ${ }^{16}$

The articles included in this study pointed to that elderly people living in institutions of permanence have functional conditions individuals, which results in a lower rate of falls and fewer health consequences when compared to those who live in communities. ${ }^{16,17}$
One of the most important injuries that affects this population is the occurrence of falls, considered a public health problem due to high index of the event and because it is associated to multiple factors, due to the condition of the health of the elderly, lack of qualification of health professionals and the inadequacies infrastructure of these institutions. ${ }^{12,17}$

Thus, the presence of chronic-degenerative diseases (hypertension, diabetes, arthritis, osteoporosis and dementia) is considered one of causes that contribute to the hospitalization of the institutionalized elderly people, especially when are associated with the episode of falls. The process of sickness of elderly people residing in the asylum context is also interconnected with medication administration and with inefficiency of monitoring that individual by the health team, which may influence the number of occurrences of falls. ${ }^{13,17}$

The physiological changes resulting from the can affect performance visual and lead to risk of falls. O impaired visual acuity, increased susceptibility light and instability in the fixation of the gaze are factors that can cause loss of balance, since the sensory function of the vision helps in the mechanism of postural control. ${ }^{14,18}$

In addition, visual impairments when associated with poor ambient lighting and the inadequate infrastructure of asylum institutions, may predispose to slipping and skidding in uneven areas. It is well known that the falls occurring in ILPI, occur in rooms and bathrooms, and emphasized the need for of these spaces by the health team. ${ }^{1-3,8}$

It is observed that the occurrence of falls in institutions is related to sex, as that most of the articles selected indicated prevalence among women. Although there is still no consensus among scholars in the area in question, it is believed that the elderly are generally better off that the elderly and, consequently, greater exposure to the risk of falls. ${ }^{18}$

The health conditions of elderly people residing in in nursing homes reinforce the importance of and reevaluation by gerontology professional geriatrician, both from the point of view of efficiency and quality of service provided, and for research purposes. The necessity measures may lead to impaired actions. promotion of health, prevention and rehabilitation of these elderly people. ${ }^{3,5,16,17}$

In the case of institutionalized elderly, the need for qualification is emphasized. of the health team, in particular the Nursing, for being one of the most present in the asylum institutions and four pointed out that interventions in the asylum have a multiprofessional character. These results indicate the importance of integrated actions between the health professionals in the health care of the old man. ${ }^{19}$

The adoption of health education activities can be a valuable tool in preventing the risk of falls in ILPI. According to research, such actions are considered effective in promoting self-care among the elderly and are capable of promoting collective benefits among residents of long-term institutions. ${ }^{19}$

In general, all the articles selected with the theme in question, worked on the perspective of reflecting on the falls in the elderly and their potentiating factors. However, the risk of falls was cited in all studies as one of the main causes of functional disability. ${ }^{1,3,18,19}$

\section{Conclusion}

From this study, it can be concluded that the occurrence of falls in the elderly can result in a relevant health problem. Based on the 
reflection and literary methodological analysis carried out, it has been found that a wide variety of consequences may occur after an episode of decline. These can involve physical damage, such as tissue injuries, injuries and fractures, functional decline and increased dependence and psychosocial issues such as fear of falling, isolation and loss of autonomy.

Considering the seriousness of several of these consequences, effective fall prevention programs are needed. In addition to these, it is also important to implement rehabilitation programs after falls, with the aim of preventing or minimizing the occurrence of such repercussions, showing that falls can have important implications for the elderly family and for society.

The falls do not only generate physical repercussions in the elderly. The fear of falling is a consequence highlighted by several authors in this study and is related to quality of life of the elderly. Fear after falling can bring with it not only the fear of further falls, but also of being injured, being hospitalized, being detained, having health declines, and becoming dependent on others for self-care or life activities daily.

It is important to clarify that improving the subject will bring a number of benefits to the health sciences and in particular to the health of the elderly. In this way, the exploration of the subject is of benefit to the academy and the health sciences in the general context. Unveiling by diverse studies will help in the improvement of the methodological ideas, promotion, rehabilitation and contextualization of the health.

\section{Acknowledgements}

None.

\section{Conflict of interest}

Author declares that there is no conflict of interest.

\section{References}

1. Coimbra VLMM, Marque EMBG, Requeijo CAL, et al. Community Intervention in elderly population: a fall prevention project. International Archives of Medicine. 2018;11:1755-7682.

2. Maciel GMC, Silva HTA, Gonçalves RG, et al. Frailty assessment and it association with sociodemographic and health characteristics in community elderly. International Archives of Medicine. 2017;10:1755-7682.

3. De Lima AK, Alves MRR, Pires de Sá CMC, et al. Nursing professional's working load given to the elderly at the intensive unit care. International Archives of Medicine. 2017;10:1755-7682.
4. Araújo M, Mauricio TF, Moreira RP, et al. Nursing diagnosis of impaired physical mobility in elderly people at primary health care. International Archives of Medicine. 2017;10:1755-7682.

5. Oliveira CDB, Deolino SMA, Dutra MOM, et al. Abusive consumption of alcohol by elderly. International Archives of Medicine. 2017;10:17557682 .

6. Souza MC, LinsDR, Saraiva CNR, et al. Risk factors related to falls in elderly: a reflective study. MOJ Gerontol Ger. 2018;93(4):131-132.

7. Souza MC, Araújo HS, Silva, TTSM, et al. Treatment of venous ulcer in the elderly: implications for nursing. MOJ Gerontol Ger. 2018;3(4):287-291.

8. Rubio FM, sky MAT, Salcedo EEO. Labor reintegration: approach to the reality of the transplanted patient. MOJ Gerontol Ger. 2018;3(4):301-303.

9. Leguizamón MAS, Kockmann S. Aging in the latin america and caribbean: two positions as we are in Paraguay. MOJ Gerontol Ger. 2018;3(4):297-299.

10. Pérez JP. Age-related slow fundamental recovery VO2 kinetics during submaximal exercise. MOJ Gerontol Ger. 2018;3(4):280-285.

11. Moller J, Hallqvist J, Laflamme L, et al. Emotional stress as a trigger of falls leading to hip or pelvic fracture. Results from the ToFa study - a case-crossover study among elderly people in Stockholm, BMC Geriatr. 2009;9:7.

12. Ferretti F, Lunardi D, Bruschi L. Causas e consequências de quedas de idosos em domicílio. Fisioter Mov. 2013;26(4):753-762.

13. Lima MM, Reibnitz KS, Kloh D, et al. The pedagogical relationship in practical-reflexive education: characteristic elements of teaching integrality in nurse education. Texto Contexto Enferm. 2018;27(2):e1810016.

14. Machado AF. Dobras cutâneas: localização e procedimentos. Motricidade. 2008;4:41-45.

15. World Health Organization. WHO global report on falls prevention in older age. Geneva; 2007.

16. Edelberg H. Falls and function. How to prevent falls and injuries in patients with impaired mobility. Geriatrics. 2001;56(3):41-45.

17. Maciel A. Quedas em idosos: um problema de saúde pública desconhecido pela comunidade e negligenciado por muitos profissionais da saúde e por autoridades sanitárias brasileiras. Rev Med Minas Gerais. 2010;20(4):554-557.

18. Reis JP, Macera CA, Araneta MR, et al. Comparison of overall obesity and body fat distribution in predicting risk of mortality. Obesity. 2009;17(6):1232-1239.

19. Gibson R. Principles of nutritional assessment. 2nd ed. Oxford: Oxford University Press; 2005. 